\title{
ŞEKER FABRİKALARINDAKİ ENERJİ SANTRALLERİ İÇİN TERMOEKONOMİK ANALİZ YÖNTEMİ
}

\author{
Tolga TANER*, Mecit SIVRİOĞLU** \\ *Aksaray Üniversitesi, Aksaray Teknik Bilimler MYO, Motorlu Araçlar ve Ulaştırma Teknolojisi Bölümü, \\ Aksaray, Türkiye \\ **Gazi Üniversitesi, Mühendislik Fakültesi, Makine Mühendisliği Bölümü, Ankara, Türkiye \\ tolgataner@aksaray.edu.tr, mecits@gazi.edu.tr
}

(Geliş/Received: 28.02.2013; Kabul/Accepted: 22.04.2014)

\section{ÖZET}

$\mathrm{Bu}$ çalışma, şeker fabrikalarındaki buhar enerji güç santrallerine termoekonomik analiz yönteminin uygulanması üzerinedir. Örnek olarak Konya Çumra Şeker Fabrikası ele alınmış ve termoekonomik yöntem uygulanmıştır. Termoekonomik yöntem olarak eşitlik (ekserjik maliyet denge) yöntemi uygulanmıştır. Buhar enerji güç santralindeki ekserji hesaplamaları dikkate alınarak mevcut duruma göre senaryolar üretilmiştir. Bu çalışmadaki amaç; şeker fabrikalarında yoğun olarak kullanılan ve üretilen enerjiden en iyi şekilde faydalanıp fabrikanın karlılığını arttırmaktır. Bu çalışma ile buhar enerji güç santralindeki mevcut gücün arttırılması amaçlanarak, ekserji maliyetinin düşürülmesi hedeflenmiştir. Bu çalışmada, fabrikada mevcut buhar enerji güç santralinden 8 [MW] farklı güçlerde senaryolar düzenlenmiştir. Buhar enerji güç santrali için 14 [MW]'lık senaryo düzenlendiğinde mevcut kurulu buhar enerji güç santraline göre ekserji maliyetinin $1,370 \times 10^{\wedge}-5[€ / \mathrm{kJ}]$ 'e düştügü gözlemlenmiştir.

Anahtar kelimeler: Enerji, ekserji, termoekonomik, eşitlik (ekserjik maliyet denge) yöntemi

\section{THERMOECONOMIC ANALYSIS FOR THE POWER PLANTS OF SUGAR FACTORIES}

\begin{abstract}
This study focuses on the application of thermoeconomic analysis for the steam energy power plants of sugar factories. Konya Cumra Sugar Factory was considered as a sample sugar factory for which the thermoeconomic analysis was applied. The equality method (balance of the exergetic-costing method) was applied for thermoeconomic calculations. Exergy calculations of the steam energy power plant are considered to produce some scenarios compared to the current situation. The aim of this study is to increase the profit ratio of the sugar factory by achieving the most efficient usage of energy that is intensively used and produced within the factory. With this study we aimed to decrease the cost of exergy by increasing the present power of the steam energy power plant. In this study, some scenarios were considered with different powers compared to the present steam energy power plant of the factory. When $14[\mathrm{MW}]$ was selected for the steam energy power plant, we observed that the cost of the exergy decreased to $1.370 \times 10^{\wedge}-5[€ / \mathrm{kJ}]$ according to the present of the steam energy power plant.
\end{abstract}

Keywords: Energy, exergy, thermoeconomic, equality (balance of the exergetic-costing method) method

\section{GIRIŞS (INTRODUCTION)}

Şeker fabrikalarında, şeker üretimi süreç aşamalarından ötürü enerjiye yoğun olarak ihtiyaç bulunmaktadır. Bunu karşılayabilmek için buhar enerjisinin üretilmesi gerekmektedir. $\mathrm{Bu}$ üretilen enerjiden verimli bir şekilde (ekserji) yararlanabilmek için termoekonomik analizinin iyi yapılması gerekmektedir. Bu çalışmada, ekserji maliyet denge yöntemi üzerinde durularak fabrika karlılığının arttırılması amaçlanmıştır. Gıda sektöründe enerji ekonomisinin yanında, ekserji ekonomisinin de değerlendirilmesi önemlidir. Ekserjinin belirlenmesi ile ekserjinin maliyeti ortaya çıkar. Bunu yapmak için 
termoekonomik analiz yöntemlerinin seçilmesi çok önemlidir. Termoekonomik analizin esası, maliyetleri en aza indirgemek için yapılan analizler eşliğinde değişik senaryolar üzerinde durulmasıdır. İyi bir iyileştirme için fabrikanın mevcut durumu ile uygulanabilir senaryolara ait termoekonomik analiz sonuçları karşılaştırılarak, en verimli olan senaryo seçilmelidir. Bunun için; Türkiye'nin en büyük entegre tesislerinden olan Konya Çumra şeker fabrikası bu çalışmada örnek olarak ele alınmıştır. Konya Çumra şeker fabrikasının enerji ve ekserji analiz sonuçlarına göre termoekonomik analiz uygulanarak, fabrika enerji ekonomisi için ne yapılması gerektiği ortaya çıkarılmıştır. Fabrikanın uygulanan termoekonomik eşitlik (ekserjik maliyet denge yöntemi) yöntemi ile karlılığ ve değişik senaryolar düzenlenmiştir. $\mathrm{Bu}$ yöntemde elektrik jeneratörü ile türbin buhar ekserji maliyetlerinin bulunması amaçlanmıştır. Termoekonomik analiz tanım, olarak ekserji analizine dayanarak ekonomik maliyetinin çıkarılmasıdır. Buna göre termoekonomik analiz yaklaşımı iki şekilde incelenebilir [1];

I. Proses akışındaki enerji analizini temel alan termoekonomik analiz yöntemleri [2],

II. Maliyet limitlerinin bulunması ile enerji akışı tüm fabrika için ekserjik analiz yöntemlerinin uygulanmasidır $[3,4]$.

Yukarıdaki yöntemlerden ikincisi baz alınarak termoekonomik analiz uygulanmıştır. Bu yöntem de üç değişik şekilde uygulanabilmektedir $[2,4,5]$.

1. Bağımsız otonom yöntemi

2. Ekstrasyon yöntemi

3. Eşitlik yöntemi (ekserjik maliyet denge yöntemi)

$\mathrm{Bu}$ uygulamalardan yöntem olarak eşitlik yöntemi seçilmiştir [2, 4, 5, 6, 7]. Eşitlik yöntemi, ekserjik maliyet denge yöntemidir. $\mathrm{Bu}$ yöntem ekserji maliyetinin hesaplanması ile ifade edilir. Eşitlik yönteminde, basınç buhar maliyeti ile türbin sermaye eşitliği (dengesi) dikkate alınarak ekserjik maliyetleri hesaplanır. Bu sebepten ötürü, bu çalışmada örnek olarak seçilen fabrikanın ekserji maliyeti ile kar ve zarar hesabının yapılması amaç edinilmiştir. Önce proseslerin enerji ve ekserji analizleri bulunmuş daha sonra bulunan sonuçlara göre ekserjik maliyet denge yöntemi uygulanmıştır.

\section{YÖNTEM ve DENKLEMLER (METHOD AND EQUATIONS)}

Ekserji ekonomisi diğer adıyla termoekonomik analiz (ekserji kayıplarından kaynaklanan ekonomik kayıplar), ekserji maliyetlerinin hesaplanması ile yapılır [1]. $\mathrm{Bu}$ çalışmada termoekonomik hesaplamalar aşağıdaki denklemler ile gerçekleştirilmiştir. Bu denklemler Valero Metodu olarak ekserji ekonomisi yöntemine göre yazılmıştır
$[7,8,9,10,11,12]$. Tüm akış sistemindeki ekserjik maliyet [13];

Birim ekserjik maliyeti (exc) [13]:

$\mathrm{exc}=\frac{\mathrm{EXC}}{\mathrm{ex}}$

\section{Ekserji birim termoekonomik maliyeti (tec) [13]:}

Termoekonomik uygulamalarda kullanılan, birim ekserji başına termoekonomik maliyeti aşağıdaki denklemden bulunur.

tec $=\frac{\mathrm{TEC}}{\mathrm{ex}}$

Tesiste akışkan yataklı kazan (1si), türbin termal ekserji ve buhar üretimi için aşağıdaki ekserji maliyet formülü kullanılmıştır $[4,14]$.

$\dot{\mathrm{C}}_{\mathrm{K}, \mathrm{o}}=\dot{\mathrm{C}}_{\mathrm{en}}+\dot{\mathrm{Z}}$

$\mathrm{Bu}$ formül kullanılarak bazı kabullerle birlikte termoekonomik hesaplamalar yapılmıștır. Önce akışkan yataklı kazandaki türbin mil gücü hesaplanmıştır. Daha sonra türbin oransal verimlilikleri hesaplanmıştır. $\mathrm{Bu}$ hesaplamalarda kullanılan kabuller ise şu şekildedir [4];

-Tüm basınç kayıpları (Türbin besleme pompa kayıpları ve diğer yedek ekipmanların kayıpları) ihmal edilmiştir.

-Tüm elektrik ve mekanik iş sebebi ile oluşan 1s1 kayıpları ihmal edilmiştir.

Hesaplamalar şu şekilde yapılmıştır [1, 4, 14];

Türbin mil gücü:

$\dot{\mathrm{W}}_{\mathrm{mil}}=\frac{\dot{\mathrm{W}}_{\mathrm{el}}}{\eta_{\mathrm{me}} \eta_{\mathrm{el}}}$

Kazan yakıt miktarl

$\dot{\mathrm{m}}_{\mathrm{K}}=\frac{\dot{\mathrm{m}}_{\mathrm{b}}\left(\mathrm{h}_{\mathrm{K} 5, \mathrm{o}}-\mathrm{h}_{\mathrm{K} 4, \mathrm{i}}\right)}{\Psi_{\mathrm{Li}} \times \eta_{\mathrm{K}}}$

Akışkan yataklı kazan ekserji girişi ise şu şekilde hesaplanmıştır;

$\dot{\mathrm{Ex}}_{\mathrm{i}, \mathrm{K}}=\dot{\mathrm{m}}_{\mathrm{K}} \Psi_{\mathrm{Li}}$

Akışkan yataklı kazan oransal verimliliği [4]:

$\varphi_{\mathrm{K}}=\frac{\dot{\mathrm{Ex}} \mathrm{x}_{1 \mathrm{~T}}}{\dot{\mathrm{Ex}} \mathrm{i}_{\mathrm{iK}}}$

Termoekonomik analiz uygulanırken maliyet analiz yöntemlerinden eşitlik yönteminin uygulanacağından yukarıda bahsedilmişti. Eşitlik yöntemi (ekserjik maliyet denge yöntemi) kar etme temeline 
dayanmaktadır. Kar ise; şeker üretimi satış gelirleri ile işletme maliyetleri arasındaki fark demektir. Ekserjik maliyet denge yöntemi, türbin mil gücü ile türbin çıkış ekserjisi, maliyetlerinin eşit olarak alınmasını ifade eder $[5,7,14]$.

Eşitlik yönteminde türbin eşitlik oransal verimliliği aşağıdaki şekilde bulunur $[4,5,7]$;

$\varphi_{\mathrm{es}, \mathrm{T}}=\frac{\dot{\mathrm{W}}_{\mathrm{mil}}+\dot{\mathrm{Ex}}_{2 \mathrm{~T}}}{\dot{\mathrm{Ex}}_{1 \mathrm{~T}}}$

Türbin ve jeneratör oransal ekserjik çıkış verimlilikleri sırasıyla $\left(\varphi_{\text {ex,T }}\right.$ ve $\left.\varphi_{\mathrm{J}}\right)$ şu şekilde hesaplanır [4];

$$
\begin{aligned}
& \varphi_{\mathrm{ex}, \mathrm{T}}=\frac{\dot{\mathrm{W}}_{\mathrm{mil}}}{\dot{\mathrm{Ex}}_{1 \mathrm{~T}}-\dot{\mathrm{Ex}}_{2 \mathrm{~T}}} \\
& \varphi_{\mathrm{J}}=\frac{\dot{\mathrm{W}}_{\mathrm{el}}}{\dot{\mathrm{W}}_{\mathrm{mil}}}
\end{aligned}
$$

Bulunan oransal verimlilikler ile mil fabrika kurulu güç yatırım değerlerine göre termoekonomik ekserjik maliyet hesaplamaları yapılmıştır. Sermaye iyileştirme faktörü $\left(a^{c}\right)$ bulunarak tek tek akışkan yataklı kazan, türbin ve elektrik jeneratörü yatırım oranları belirlenmiştir [1, 14, 15, 16, 17, 18, 19, 20$]$.

Sermaye iyileștirme faktörü (amortisman çarpani) $[14,15,16,17,18,19,20]$ :

$\mathrm{a}^{\mathrm{c}}=\mathrm{CRF}=\frac{\mathrm{i}(1+\mathrm{i})^{\mathrm{n}}}{(1+\mathrm{i})^{\mathrm{n}}-1}$

Sermaye iyileştirme faktörü bulunduktan sonra ayrı ayrı akışkan yataklı kazan, türbin ve elektrik jeneratörü sermaye yatırım oranları bulunur.

Akıșkan yataklı kazan, türbin ve elektrik jeneratörü için sermaye yatırım oranı genel denklemi $[5,14,15$, 16]:

$$
\dot{\mathrm{Z}}_{\omega}=\frac{\mathrm{a}^{\mathrm{c}}}{\mathrm{n}_{\mathrm{H}}} \frac{\mathrm{C}_{\omega}}{3600}
$$

Daha sonra kazan giriş birim ekserji maliyeti hesaplaması şu şekilde yapılmıştır $[4,5,17,18,19$, 20, 21].

$$
\mathrm{c}_{\mathrm{ex}, \mathrm{i}}=\frac{\mathrm{C}_{\mathrm{Li}}}{\psi_{\mathrm{Li}}}
$$

Akışkan yataklı kazan sermaye yatırım oranı:

$$
\dot{\mathrm{Z}}_{\mathrm{K}}=\frac{\mathrm{a}^{\mathrm{c}}}{\mathrm{n}_{\mathrm{H}}} \frac{\mathrm{C}_{\mathrm{K}}}{3600}
$$

Türbin sermaye yatırım orant:

$$
\dot{\mathrm{Z}}_{\mathrm{T}}=\frac{\mathrm{a}^{\mathrm{c}}}{\mathrm{n}_{\mathrm{H}}} \frac{\mathrm{C}_{\mathrm{T}}}{3600}
$$

Elektrik jeneratör sermaye yatırım orani:

$$
\dot{\mathrm{Z}}_{\mathrm{J}}=\frac{\mathrm{a}^{\mathrm{c}}}{\mathrm{n}_{\mathrm{H}}} \frac{\mathrm{C}_{\mathrm{J}}}{3600}
$$

Essitlik yöntemi kullanarak ekserji maliyetinin hesaplanmast:

$\mathrm{Bu}$ yöntem fabrika tüm gelir giderlerini içeren bir yöntemdir. Buna göre kurulu güç santralinin tüm gider denklemi ise $[4,5,17,18,19,20,21]$;

$$
\dot{\mathrm{Ex}}_{\mathrm{IK}} \mathrm{c}_{\mathrm{ex}, \mathrm{i}}+\left(\dot{\mathrm{Z}}_{\mathrm{K}}+\dot{\mathrm{Z}}_{\mathrm{T}}+\dot{\mathrm{Z}}_{\mathrm{J}}\right)=\dot{\mathrm{Ex}}_{2 \mathrm{~T}} \dot{\mathrm{C}}_{2 \mathrm{~T}, \mathrm{ex}}+\dot{\mathrm{W}}_{\mathrm{el}} \dot{\mathrm{C}}_{\mathrm{J}, \mathrm{ex}}
$$

Türbin çıkış ekserji birim maliyeti elektrik jeneratör ekserji birim maliyetine eşit olduğu kabul edilerek yeni bir denklem oluşturulur. Yeni denklem şu şekildedir $[4,5]$;

$\dot{\mathrm{C}}_{2 \mathrm{~T}, \mathrm{ex}}=\dot{\mathrm{C}}_{\mathrm{J}, \mathrm{ex}}=\frac{\left.\dot{\mathrm{Ex}} \mathrm{x}_{\mathrm{IK}} \mathrm{c}_{\mathrm{ex}, \mathrm{i}}+\dot{\mathrm{Z}}_{\mathrm{K}}+\dot{\mathrm{Z}}_{\mathrm{T}}+\dot{\mathrm{Z}}_{\mathrm{J}}\right)}{\dot{\mathrm{Ex}}_{2 \mathrm{~T}}+\dot{\mathrm{W}}_{\mathrm{el}}}$

İşletmenin yukarıdaki denklemlere göre yapılması gereken maliyet hesaplamalarının yanı sira yıllık kazançlarına göre de geri ödeme süresinin çıkarılması gerekmektedir. Yatırım maliyetlerinin karşılanması için geri ödeme süresi denklemi aşağıdaki gibidir [7, $16,21]$;

$\mathrm{GOS}=\frac{\mathrm{C}_{\mathrm{TPL}}}{\mathrm{c}_{\text {net }}}$

$\mathrm{Bu}$ bulunan sonuçlarla işletmenin mevcut durumu ile düzenlenen senaryolar ele alınarak karşılaştırılması yapılmıştır. Hangi senaryo iyi ise ona göre planlama yapilmalidir.

\section{TERMOEKONOMIKK ANALİZ HESAPLAMA SONUÇLARI (RESULTS OF CALCULATIONS USED IN THERMOECONOMIC ANALYSIS)}

Termoekonomik analizler örnek şeker fabrikasına (Konya Çumra Şeker Fabrikası) uygulandıktan sonra sonuçlar tablolar halinde sunulmuştur [Bakınız Tablo 1-7]. Bu bulunan sonuçlarla (Mevcut durum $8 \mathrm{MW}$ kurulu güce göre yapılan hesaplamalar) işletmenin mevcut durumu ortaya konmuş ve daha sonra bu durumdan farklı olacak şekilde bazı senaryolar düzenlenerek karşılaştırılmaları yapılmıştır. Seçilen senaryolarda 10, 12 ve 14 [MW]'lık kurulu güç buhar santralleri ele alınmış ve ekserji birim maliyetleri Excel bilgisayar paket programında hesaplanmıştır. Excel programinda bulunan sonuçlar tablo haline getirilmiştir. Enerji üretim süreci enerji ve ekserji hesaplamaları sonucunda bulunan ekserjiler ve kütle debiler 10,12 ve 14 [MW] senaryo güçlerine göre bulunarak Tablo 1'de verilmiştir [1]. 
Tablo 1. Mevcut kurulu güç ile 10, 12 ve 14 [MW] senaryo güçleri için fabrika üretim süreci ekserji ve kütle sonuçları (Exergy and mass results of factory production processes for the current power and 10, 12 and 14 [MW] scenario power plants)

\begin{tabular}{|c|c|c|c|c|c|c|}
\hline $\begin{array}{c}\dot{\mathrm{P}}_{\mathrm{el}}[\mathrm{MW}] \\
\text { güç }\end{array}$ & $\begin{array}{l}\dot{\mathrm{P}}_{\text {mil }}[\mathrm{kW}] \text { türbin } \\
\text { mil gücü }\end{array}$ & $\begin{array}{c}\dot{\mathrm{m}}_{\mathrm{b}}[\mathrm{kg} / \mathrm{s}] \\
\text { türbin buhar kütlesel } \\
\text { debisi }\end{array}$ & $\begin{array}{c}\dot{\mathrm{m}}_{\mathrm{K}}[\mathrm{kg} / \mathrm{s}] \text { kazan } \\
\text { buhar kütlesel } \\
\text { debisi }\end{array}$ & $\begin{array}{c}\dot{E x}_{\mathrm{i}, \mathrm{K}}[\mathrm{kW}] \text { kazan } \\
\text { ekserji girişi }\end{array}$ & $\begin{array}{l}\dot{E x}_{1 \mathrm{~T}}[\mathrm{~kW}] \text { türbin } \\
\text { ekserji girişi }\end{array}$ & $\begin{array}{l}\dot{E x}_{2 \mathrm{~T}}[\mathrm{~kW}] \text { türbin } \\
\text { ekserji çı1kışı }\end{array}$ \\
\hline 8 & 8329 & 15,27 & 4,234 & 36695 & 22526 & 12555 \\
\hline 10 & 10412 & 19,09 & 5,294 & 45874 & 28142 & 15685 \\
\hline 12 & 12494 & 22,90 & 6,350 & 55030 & 33672 & 18767 \\
\hline 14 & 14577 & 26,72 & 7,409 & 64210 & 39326 & 21918 \\
\hline
\end{tabular}

Tablo 2. Mevcut kurulu güç ile 10, 12 ve 14 [MW] senaryo güçleri için kazan, türbin ve jeneratör oransal verimlilik sonuçları (The results of efficiency ratios of the boiler, turbine and generator for the current power and 10, 12 and 14 [MW] scenario power plants)

\begin{tabular}{|c|c|c|c|c|}
\hline$\dot{\mathrm{P}}_{\mathrm{el}}[\mathrm{MW}]$ güç & $\begin{array}{c}\varphi_{\mathrm{K}}, \text { kazan oransal } \\
\text { verimlilik }\end{array}$ & $\begin{array}{c}\varphi_{\mathrm{es}, \mathrm{T}} \text { türbin oransal çıkış } \\
\text { verimliliği (eş.metod) }\end{array}$ & $\begin{array}{c}\varphi_{\mathrm{ex}, \mathrm{T}} \text { türbin oransal ekserji } \\
\text { verimliliği }\end{array}$ & $\varphi_{\mathrm{J}}$ jeneratör verimlilik oranı \\
\hline 8 & 0,614 & 0,927 & 0,835 & 0,96 \\
\hline 10 & 0,613 & 0,927 & 0,836 & 0,96 \\
\hline 12 & 0,612 & 0,928 & 0,838 & 0,96 \\
\hline 14 & 0,612 & 0,928 & 0,837 & 0,96 \\
\hline
\end{tabular}

Tablo 3. Mevcut kurulu güç ile 10, 12 ve 14 [MW] senaryo güçleri için kazan, türbin ve jeneratör yatırım maliyetleri (The investment costs of boiler, turbine and generator for the current power and 10, 12 and 14 [MW] scenario power plants).

\begin{tabular}{|c|c|c|c|c|}
\hline$\dot{\mathrm{P}}_{\mathrm{el}}[\mathrm{MW}]$ güç & $\begin{array}{c}\mathrm{C}_{\mathrm{K}}[€] \text { kazan yatırım } \\
\text { maliyeti }\end{array}$ & $\begin{array}{c}\mathrm{C}_{\mathrm{T}}[€] \text { türbin yatırım } \\
\text { maliyeti }\end{array}$ & $\begin{array}{c}\mathrm{C}_{\mathrm{J}}[€] \text { elk.jen. yatırım } \\
\text { maliyeti }\end{array}$ & $\begin{array}{c}\mathrm{C}_{\mathrm{TPL}}[€] \text { toplam yatırım } \\
\text { maliyeti }\end{array}$ \\
\hline 8 & 15000000 & 9000000 & 4000000 & 28000000 \\
\hline 10 & 17000000 & 10000000 & 5000000 & 32000000 \\
\hline 12 & 19000000 & 11000000 & 6000000 & 36000000 \\
\hline 14 & 21000000 & 12000000 & 7000000 & 40000000 \\
\hline
\end{tabular}

Tablo 4. Mevcut kurulu güç ile 10, 12 ve 14 [MW] senaryo güçleri için kazan, türbin ve jeneratör sermaye yatırım oranları ve ekserji maliyeti (The capital investment rates and cost of exergy fort he current power and 10, 12 and 14 [MW] scenario power plants)

\begin{tabular}{|c|c|c|c|c|c|c|c|}
\hline$\dot{\mathrm{P}}_{\mathrm{el}}[\mathrm{MW}]$ güç & $\begin{array}{c}\mathrm{n}[\mathrm{y} 1 \mathrm{l}] \\
\text { yatırımın } \\
\text { ekonomik } \\
\text { ömrü }\end{array}$ & $\begin{array}{c}\mathrm{n}_{\mathrm{H}}[\mathrm{h} / \mathrm{y} 1 \mathrm{l}] \\
\text { yıllık çalışma } \\
\text { süresi }\end{array}$ & $\begin{array}{l}a^{c} \text { sermaye } \\
\text { iyileştirme } \\
\text { faktörü }\end{array}$ & $\begin{array}{c}\mathrm{Z}_{\mathrm{K}}[€ / \mathrm{s}] \text { kazan } \\
\text { sermaye yatırım } \\
\text { oranı }\end{array}$ & $\begin{array}{c}\mathrm{Z}_{\mathrm{T}}[€ / \mathrm{s}] \text { türbin } \\
\text { sermaye yatırım } \\
\text { oranı }\end{array}$ & $\begin{array}{c}\mathrm{Z}_{\mathrm{J}}[€ / \mathrm{s}] \text { elk.jen. } \\
\text { sermaye } \\
\text { yatırım oranı }\end{array}$ & $\begin{array}{c}\mathrm{c}_{\mathrm{ex}, \mathrm{i}}[€ / \mathrm{kJ}] \\
\text { ekserji giriş } \\
\text { birim maliyeti }\end{array}$ \\
\hline 8 & 20 & 3600 & 0,1175 & 0,1359 & 0,0816 & 0,0363 & $2,02 \times 10^{\wedge}-6$ \\
\hline 10 & 20 & 3600 & 0,1175 & 0,1541 & 0,0906 & 0,0453 & $2,02 \times 10^{\wedge}-6$ \\
\hline 12 & 20 & 3600 & 0,1175 & 0,1722 & 0,0997 & 0,0544 & $2,02 \times 10^{\wedge}-6$ \\
\hline 14 & 20 & 3600 & 0,1175 & 0,1903 & 0,1088 & 0,0634 & $2,02 \times 10^{\wedge}-6$ \\
\hline
\end{tabular}

Yukarıdaki tabloda verilen sonuçlara göre kazan, türbin ve jeneratör oransal verimlilikleri sırasıyla Excel programında hesaplanarak sonuçlar Tablo 2'de verilmiştir. $\mathrm{Bu}$ oranlar yatırım maliyetleri hesaplamalarında kullanılan oranlardır. Daha sonra pazar araştırması ve fabrika çalışması sırasında alınan bilgiler eşliğinde bulunan buhar enerji güç santrali yatırım maliyetleri ve toplam yatırım maliyeti Tablo 3'de verilmiştir.
$\mathrm{Bu}$ yatırım maliyetlerine göre hesaplanan sermaye iyileştirme faktörü (amortisman çarpanı) ve kazan, türbin ve jeneratör sermaye yatırım oranları ile ekserji giriş birim maliyetleri Excel programında hesaplatılarak sonuçlar Tablo 4'de gösterilmiştir. Bulunan sermaye yatırım oranları ile hesaplamalar yapilarak termoekonomik ekserji maliyet hesaplamalarının eşitlik yönteme göre elde edilen sonuçları Tablo 5'de verilmiştir. 
Tablo 5. Mevcut kurulu güç ile 10, 12 ve 14 [MW] senaryo güçleri için ile termoekonomik analiz (The thermoeconomic analysis for the current power and 10, 12 and 14 [MW] scenario power plants)

\begin{tabular}{|c|c|c|c|c|}
\hline \multirow{2}{*}{$\begin{array}{c}\dot{\mathrm{P}}_{\mathrm{el}}[\mathrm{MW}] \\
\text { güç }\end{array}$} & \multicolumn{4}{|c|}{ Eşitlik Yöntemi } \\
\cline { 2 - 5 } & $\begin{array}{c}\mathrm{C}_{\mathrm{J}, \mathrm{ex}}[€ / \mathrm{kJ}] \text { elk.jen. ekserji } \\
\text { maliyeti }\end{array}$ & $\begin{array}{c}\mathrm{C}_{2 \mathrm{~T}, \mathrm{ex}}[€ / \mathrm{kJ}] \\
\text { türbin buhar ekserji maliyeti }\end{array}$ & $\begin{array}{c}\mathrm{C}_{2 \mathrm{~T}, \mathrm{ex}}[€ / \mathrm{kWh}] \text { türbin buhar } \\
\text { ekserji maliyeti }\end{array}$ & $\begin{array}{c}\mathrm{C}_{\mathrm{J}, \mathrm{ex}}[€ / \mathrm{kWh}] \text { elk.jen. ekserji } \\
\text { maliyeti }\end{array}$ \\
\hline 8 & $1,595 \times 10^{\wedge}-5$ & $1,595 \times 10^{\wedge}-5$ & 0,05743 & 0,05743 \\
\hline 10 & $1,490 \times 10^{\wedge}-5$ & $1,490 \times 10^{\wedge}-5$ & 0,05364 & 0,05364 \\
\hline 12 & $1,422 \times 10^{\wedge}-5$ & $1,422 \times 10^{\wedge}-5$ & 0,05118 & 0,05118 \\
\hline 14 & $1,370 \times 10^{\wedge}-5$ & $1,370 \times 10^{\wedge}-5$ & 0,04934 & 0,04934 \\
\hline
\end{tabular}

$\dot{\mathrm{P}}_{\mathrm{el}}[\mathrm{MW}]$

Mevcut durum ve Senaryolar

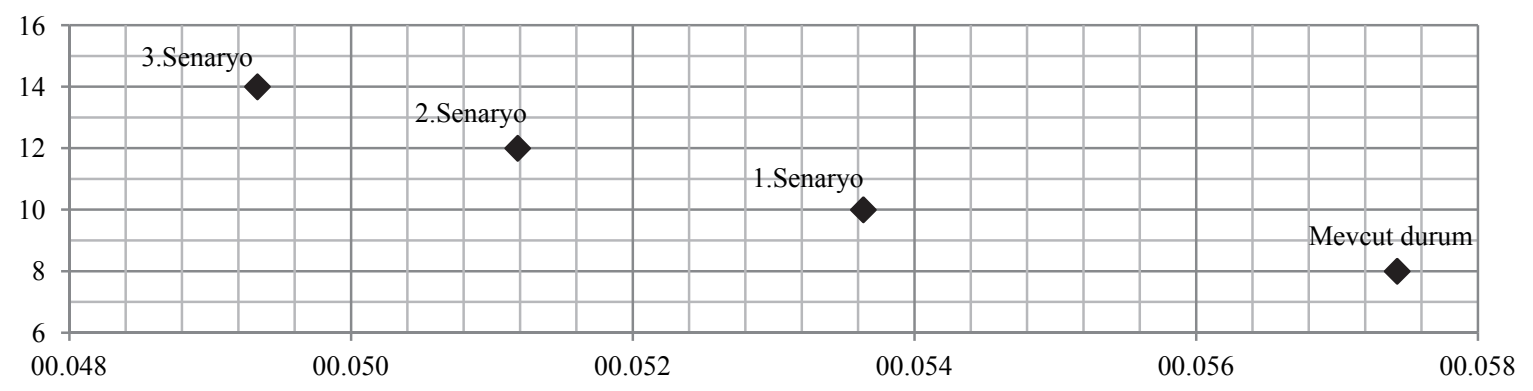

Elektrik Jeneratör Ekserji Birim Maliyeti [€/kWh]

Şekil 1. Mevcut kurulu güç ile 10, 12 ve 14 [MW] senaryo güçleri için elektrik jeneratör ekserji birim maliyeti termoekonomik analizi sonuçları (Results of thermoeconomic analysis for the unit exergy cost of electric generators for the current and 10,12 and $14[\mathrm{MW}]$ scenario Powers

$$
\dot{\mathrm{P}}_{\mathrm{el}}[\mathrm{MW}]
$$

Mevcut durum ve Senaryolar

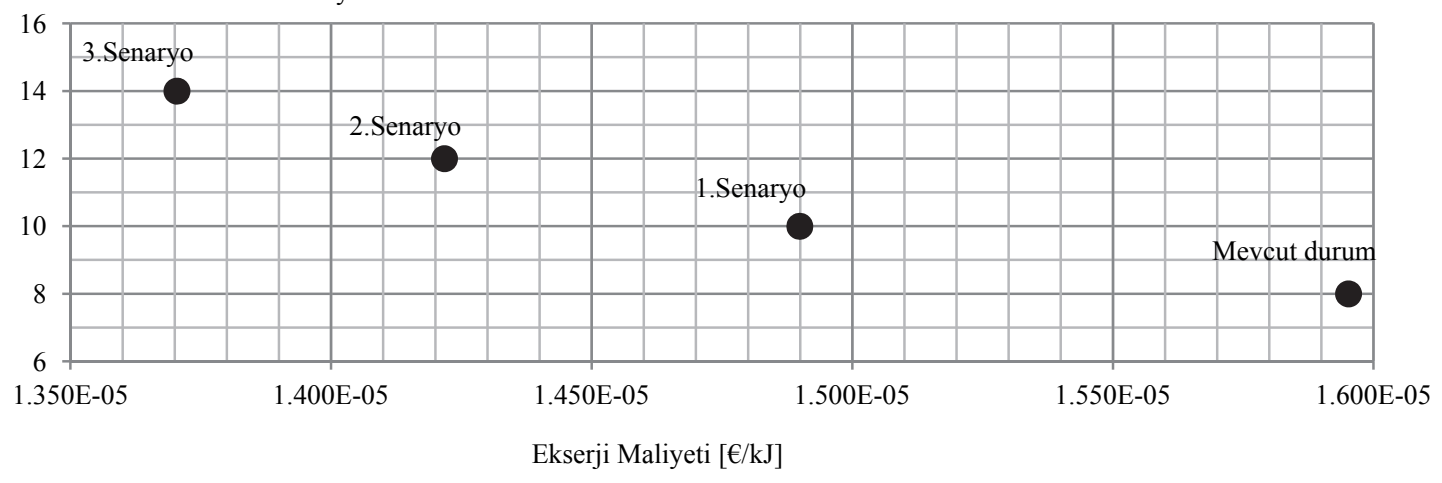

Şekil 2. Mevcut kurulu güç ile 10, 12 ve 14 [MW] senaryo güçleri için ekserji maliyeti termoekonomik analizi sonuçları (Results of thermoeconomic analysis for the exergy cost of electric generators for the current and 10,12 and 14 [MW] scenario powers)

Mevcut durum ile senaryolar karşılaştırılarak, Şekil 1 oluşturulmuştur. Bu şekle göre 8 [MW]'lık mevcut kurulu güç santralininkine göre, farklı güçlerdeki senaryoların gerektirdiği elektrik jeneratör ekserji maliyetlerinin daha düşük olduğu görülmektedir.

Ayrıca Şekil 2'de mevcut kurulu güç ile farklı güçlerdeki senaryoların gerektirdiği ekserji maliyeti ise $[€ / \mathrm{kJ}]$ olarak ele alınmıştır. Burada da farklı güçlerdeki senaryoların gerektirdiği ekserji maliyetlerinin güç arttıkça düştüğü gözlemlenmiştir. İşletmenin yukarıda hesaplanan türbin buhar ekserji ve elektrik jeneratör ekserji maliyetleri yanı sıra yıllık kazançlarına göre de, geri ödeme süreleri çıkarılmıştır. Yatırım maliyetlerinin karşılanması için geri ödeme süreleri de Tablo 6'da sıralanmıştır. 
Tablo 6. Mevcut kurulu ile senaryo güçleri geri ödeme süreleri (The amortization periods of the current and scenario power plants)

\begin{tabular}{|c|c|c|c|}
\hline$\dot{\mathrm{P}}_{\mathrm{el}}[\mathrm{MW}]$ güç & $\begin{array}{c}\mathrm{C}_{\mathrm{TPL}}[€] \text { toplam yatırım } \\
\text { maliyeti }\end{array}$ & $\begin{array}{c}\mathrm{C}_{\text {net }}[€ / \text { yll] işletmenin yaklaşık } \\
\text { ylllk net kazanc1 * }\end{array}$ & $\begin{array}{c}\text { GOS [yıl] işletmenin geri } \\
\text { ödeme süresi }\end{array}$ \\
\hline 8 & 28000000 & 10000000 & 2,80 \\
\hline 10 & 32000000 & 12493170 & 2,56 \\
\hline 12 & 36000000 & 14948109 & 2,41 \\
\hline 14 & 40000000 & 17457687 & 2,29 \\
\hline
\end{tabular}

*: Türbin ekserji çıkışına göre işletmenin yaklaşık yıllık net kazanç oransal olarak ele alınmıştır.

Tablo 7. Mevcut kurulu güç ile 10, 12 ve 14 [MW] senaryo güçleri için elektrik jeneratör ekserji maliyeti ile şeker üretimi arasındaki ilişki (Relation between the cost of electric generators and sugar production for the current and 10,12 and 14 $[\mathrm{MW}]$ scenario powers)

\begin{tabular}{|c|c|c|c|c|c|c|c|}
\hline $\begin{array}{c}\dot{\mathrm{P}}_{\mathrm{el}} \\
{[\mathrm{MW}]} \\
\text { güç }\end{array}$ & $\begin{array}{c}\mathrm{C}_{\mathrm{J}, \mathrm{ex}}[€ / \mathrm{kWh}] \\
\text { elk.jen. } \\
\text { ekserji } \\
\text { maliyeti }\end{array}$ & $\begin{array}{c}\dot{\mathrm{m}}_{\mathrm{b}}[\mathrm{kg} / \mathrm{s}] \\
\text { türbin buhar } \\
\text { kütlesel } \\
\text { debisi }\end{array}$ & $\begin{array}{c}\text { Üretim miktarı } \\
\text { mevcut ve } \\
\text { senaryo güç } \\
\text { artışı göre [ton] } \\
*\end{array}$ & $\begin{array}{c}\text { Mevcut ve } \\
\text { senaryo güç } \\
\text { yıllik ekserji } \\
\text { maliyeti } \\
{[€] * *}\end{array}$ & $\begin{array}{c}\text { Fabrika yılllk } \\
\text { şeker üretimi } \\
\text { parasal değeri [€] } \\
* * *\end{array}$ & $\begin{array}{c}\text { Şeker üretimi } \\
\text { karı [€] } * * * *\end{array}$ & $\begin{array}{c}\text { GOS [yıll] } \\
\text { işletmenin } \\
\text { geri ödeme } \\
\text { süresi }\end{array}$ \\
\hline 8 & 0,05743 & 15,27 & 288853 & 1653902 & 29385016 & 27731113 & 2,80 \\
\hline 10 & 0,05364 & 19,09 & 361114 & 1930938 & 36736081 & 34805142 & 2,56 \\
\hline 12 & 0,05118 & 22,90 & 433185 & 2211113 & 44067902 & 41856789 & 2,41 \\
\hline 14 & 0,04934 & 26,72 & 505445 & 2486505 & 51418967 & 48932462 & 2,29 \\
\hline
\end{tabular}

*: Üretim miktarları, türbinden üretilen senaryo buhar kütlesel debilerine göre hesaplanmıştır.

**: Kurulu güç yıllık ekserji maliyeti, kurulu güç ile bulunan $\mathrm{C}_{\mathrm{J}, \mathrm{ex}}$ elektrik jeneratörü ekserji maliyeti ile çarpılarak bulunmuștur.

***: www.turkseker.gov.tr şeker resmi web sitesinden beyaz-ham şeker üretim birim fiyat 101,7346 [€/ton] olarak alınmıştır. Üretim miktarının kurulu güç artış miktarı ile bu birim fiyat çarpılarak kurulan senaryolara göre fabrika yıllık şeker üretimi parasal değerleri çıkarılmıştır [22].

****: Fabrikanın bu kurulan senaryolara göre şeker üretimi karı, fabrika yıllık şeker üretimi parasal değeri ile kurulu güç yıllık ekserji maliyeti farkı ile bulunmuştur.

Ayrıca şeker fabrikasının üretimi ile buhar enerji güç santralinin elektrik jeneratör üretimi arasındaki ekserji maliyet ilişkileri mevcut kurulu gücü ile farklı senaryo güçlere göre karşılaştırılması yapılmıştır. Sonuçlar Tablo 7'de ele alınmıştır.

Tablo 7'de 14 [MW] senaryo gücü, şeker üretimine bağlı olarak elektrik jeneratör ekserji maliyeti en düşük olandır. Bunun yanı sıra şeker fabrikasının 14 [MW]'lık senaryo için; yıllık şeker üretimi parasal değerinin $51418967[€]$ ve fabrika şeker üretimi karının ise 48932462 [ $€$ ] olduğu tespit edilmiştir. Bu değer mevcut güç ve farklı senaryolardaki güçler arasındaki en iyi sonuçtur. Böylece santral gücünün artmasıyla elektrik jeneratör ekserji maliyeti lineer olarak düşmektedir. Güç değeri ile jeneratör ekserji maliyeti arasında doğrusal bir iliş̧i bulunmaktadır. Bunun nedeni ise şeker fabrikalarında çok yoğun miktarda buhar enerjisi kullanılmaktadır.

Bir başka deyişle buhar güç santrali gücü, arttırıldığ 1 zaman ekserji maliyetleri düşer. Çünkü ekserji ihtiyacı karşılanmış olur. Buna göre şeker üretiminin tüm proses aşamalarında (şeker pancarının kıyılması, ham şerbet üretimi, arıtılması, koyulaştırılması, koyu şerbetin rafinesi, nemli kristal şeker üretimi) buhar enerjisi üretimi için elektrik enerjisi üretimine ihtiyaç duyulmaktadır. $\mathrm{Bu}$ sebepten ötürü, zamana bağlı olarak buhar enerjisine sürekli olarak ihtiyaç bulunmaktadır. Bundan dolayı elektrik enerjisinin üretilmesi zamanla doğru orantılı olarak artmalıdır.

\section{SONUÇLAR (CONCLUSIONS)}

Termoekonomik analiz yönteminde ekserji hesaplamaları önemli yer tutmaktadır. Termoekonomik analiz yöntemi fabrikanın kar zarar durumunu ortaya koyabilecek bir yöntemdir. Bu çalışmada, buhar enerji güç santralinin gücünün arttırılması ile türbin ekserji maliyeti ile jeneratör ekserji maliyetinin düştüğü görülmüştür. Buhar enerji güç santrali için 14 [MW]'llk senaryo düzenlendiğinde ekserji maliyetinin $1,370 \times 10^{\wedge}-5$ [€/kJ]'e düştüğü saptanmıştır. Mevcut kurulu güç ile 14 [MW]'lık senaryo gücü karşılaştırıldığında; işletmenin yıllık net kazancının 14 [MW] senaryo gücünde daha fazla olduğu görülmüştür. İşletmenin geri ödeme süresinin hesaplanması sonucunda fabrika için en yüksek güce karşıllk gelen üçüncü senaryonun en karlı olacağı tespit edilmiştir. Şeker fabrikalarında şeker pancarından şeker elde edilmesi esnasında ham şerbet üretim, arıtma, koyulaştırma, kurutma ve soğutma proseslerden ötürü buhar enerjisine çok ihtiyaç vardır. $\mathrm{Bu}$ çalışma ile buhar enerji güç santralindeki mevcut gücün arttırılması amaçlanarak, ekserji maliyetinin düşürülmesi hedeflenmiş̧ir. Bunun için buhar enerji güç santrali çok önem arz etmektedir. Bu çalışma ile kurulu buhar enerji güç santralinin gücü arttırıldığında, ekserji maliyetlerinin düştüğü görülmüştür. Bunun anlamı; şeker fabrikalarının amortisman süresine de bağlı olarak yatırım ve işletme maliyetlerini karşıladığında, ilerleyen zamanlarda ekserji maliyetinin düşeceğini 
göstermektedir. Burada güç değeri ile türbin ve jeneratör ekserji maliyeti arasında doğrusal bir ilişki olduğu görülse de güç değerinin çevrimdeki diğer elemanların (bakım-onarım, işletme maliyetleri, çevrimdeki kayıplar gibi) ekserji maliyetleri üzerinde farklı yönlerde etkileri olacağından optimize edilmesi de gerekmektedir. Burada ise; optimize edilmiş bu güç ile ekserji maliyetlerinin düşürülebileceği görülmüştür. Fabrika buhar enerji güç santrali için uygulanacak yerel optimizasyon prosedürleri geleneksel optimizasyon yöntemlerinden daha iyi sonuç verebilir. Bunun nedeni ise daha basit matematiksel işlemlerin, ana kumanda merkezinden tüm fabrika için yapılmadan bölgesel olarak yapılmasıdır. Tesisteki tüm kütle ve enerji akışının ekserji maliyetini sağlayan termoekonomik model bir yerel optimizasyon yöntemi olup, elektrik jeneratör ve buhar üretimini de içermelidir. Bu optimizasyon, etkin bir maliyet çalışmasıdır. Tesisin karlılı̆̆ 1 için uygun olup, daha iyi bir tesis tasarlanabilir [23]. Örnek olarak bu çalışmadan görüldüğü gibi tesis gücünün arttırılmasıdır. Mevcut kurulu güç, 10, 12 ve 14 [MW] senaryo güçlerin elektrik jeneratör ekserji maliyeti ile şeker fabrikasındaki şeker üretimi arasındaki ilişki de incelenmiştir. 14 [MW] senaryo gücüne göre şeker üretimine bağlı olarak gerekli optimizasyonlar yapıldı $\breve{1}$ takdirde, elektrik jeneratör ekserji maliyetinin düşürülebileceği ve işletme karının arttırılabileceği görülmüştür. Aslında bu tip fabrikalarda (enerji yoğunluğu olan) gücün arttırılması her zaman için avantaj olmasına rağmen ilk baştaki yatırım maliyetleri fazla olmaktadır. Önemli olan ise bu yatırım maliyetlerini karşılayabilecek finansmanın büyüklüğüdür.

Sonuçta, böylesine büyük enerji harcayan şeker fabrikaları için termoekonomik analizin yapılması çok önemli olup, türbin gücünün arttırılması ile fabrika karlılığının da artabileceği görülmüştür. Bu çalışma, diğer şeker fabrikaları için de bir model oluşturabilecektir.

\section{SEMBOLLER DİZINİ (NOMENCLATURE)}

$\mathrm{c}_{\mathrm{en}} \quad$ Birim enerji maliyeti, $[€ / \mathrm{kJ}]$

$\mathrm{c}_{\mathrm{ex}} \quad$ Birim ekserji maliyeti, $[€ / \mathrm{kJ}]$

$\dot{\mathrm{C}}_{2 \mathrm{~T}, \mathrm{ex}}$ Türbin çıkış ekserji birim maliyeti, $[€ / \mathrm{kJ}]$

$\dot{\mathrm{C}}_{\mathrm{J}, \mathrm{ex}} \quad$ Elektrik jeneratör birim ekserji maliyeti, $[€ / \mathrm{kJ}]$

$\dot{\mathrm{P}}_{\mathrm{el}} \quad$ Buhar enerji gücü, [MW]

\section{Indisler (Subscripts)}

$\begin{array}{ll}\mathrm{k} & \text { Kazan } \\ \mathrm{K} & \text { Kazan } \\ \mathrm{Li} & \text { Toz linyit kömür } \\ \mathrm{J} & \text { Jeneratör } \\ \text { el } & \text { Elektrik } \\ \text { me } & \text { Mekanik } \\ \mathrm{T} & \text { Türbin }\end{array}$

$\begin{array}{ll}\text { es } & \text { Eşitlik } \\ \text { i } & \text { Giriş } \\ \text { o } & \text { Çıkş̧ } \\ \text { h } & \text { Saat } \\ \text { B } & \text { Buhar } \\ \text { 1T } & \text { Türbin girişi } \\ \text { 2T } & \text { Türbin çıkş̧ı } \\ \text { en } & \text { Birim enerji } \\ \text { ex } & \text { Birim ekserji } \\ \text { K4 } & \text { Akışkan yataklı kazan girişi } \\ \text { K5 } & \text { Akışkan yataklı kazan çıkş̧ı } \\ \text { net } & \text { Net } \\ \text { s } & \text { saniye }\end{array}$

Kisaltmalar (Abbreviations)

CRF Sermaye iyileştirme faktörü (amortisman çarpanı)

GOS Geri ödeme süresi

TPL Toplam

\section{KAYNAKLAR (REFERENCES)}

1. Taner, T., Gıda Sektöründe Enerji Verimliliği ve Enerji Yönetimi: Şeker Fabrikası Örneği, Doktora Tezi, Gazi Üniversitesi Fen Bilimleri Enstitüsü, 2013.

2. Szargut, J, Morris, D., R., Steward, F., R., Exergy Analysis Of Thermal, Chemical, And Metallurgical Processes, ISBN 3-540-18864-9, Springer-Verlag, Berlin, 1988.

3. Söğüt, Z., Oktay, Z., Karakoç, H., Yörü, Y., "Kuru Tipi Çimento Üretiminde Farin Değirmeninin Termoekonomik Analizi", Isı Bilimi ve Tekniği Dergisi 30, ISSN 1300-3615, Türkiye, 59-72, 2010.

4. Kotas, T., J., The Exergy Method Of Thermal Plant Analysis, Anchor Brendon Ltd, London, 1995.

5. Gaggioli, R. A., "Second Law Analysis for Process and Energy Engineering", In Efficiency and Costing; ACS Symposium Series; American Chemical Society, 0097-6156/83/0235-0003, 3-50, 1983.

6. Banar, K., Maliyet Muhasebesi, Anadolu Üniversitesi Yayın No: 1524, Eskişehir, 2007.

7. Kwak H. Y., Kim D.J., Jeon J. S., "Exergetic and thermoeconomic analyses of power plants", Energy, 28, 343-360, 2003.

8. Ensinas, A., Nebra, S. A., "Design Of Evaporation Systems And Heaters Networks In Sugar Cane Factories Using A Thermoeconomic Optimization Procedure", Int. J. Of Thermodynamics, 10 (3), 97105, 2007.

9. Arena A. P., Borchiellini R., "Application of different productive structures for thermoeconomic diagnosis of a combined cycle power plant", Int. J. Of Thermal Science, 38, 601-612, 1999.

10.Zaleta-Aguilar A. ve Ark., "Concept on thermoeconomic evaluation of steam turbines", Applied Thermal Engineering, 27, 457-466, 2007. 
11. Valero A. ve Ark., "Structural theory and thermoeconomic diagnosis Part II: Application to an actual power plant", Energy Conversion and Management, 43, 1519-1535, 2002.

12. Hamed O. A., Al-Washmi H. A., Al-Otaibi H. A., "Thermoeconomic analysis of a power/water cogeneration plant", Energy, 31, 2699-2709, 2006.

13. Chang, H., "Exergy analysis and exergoeconomic analysis of an ethylene process", Tamkang Journal Of Science And Engineering, China, 4 (2), 105-110, 2001.

14. Naemi S., ve Ark., "Optimum design of dual pressure heat recovery steam generator using nondimensional parameters based on thermodynamic and thermoeconomic approaches", Applied Thermal Engineering, 52, 371-384, 2013.

15. Khoshgoftar Manesh M. H., ve Ark., "Exergoeconomic and exergoenvironmental evaluation of the coupling of a gas fired steam power plant with a total site utility system", Energy Conversion and Management, 77, 469-483, 2014.

16. Elhanan, A. E., Derbentli, T., "Gaz Türbinli Kojenerasyonla Elektrik Üretimi ve Soğutma", ITÜ Mühendislik Dergisi, 6 (5-6), 47-58, 2007.

17. Rovira A., ve Ark., "Thermoeconomic optimisation of heat recovery steam generators of combined cycle gas türbine power plants considering off-design operation", Energy Conversation and Management, 52, 1840-1849, 2011.

18. Ahmadi P., Dinçer İ., "Thermodynamic analysis and thermoeconomic optimization of a dual pressure combined cycle power plant with a supplementary firing unit", Energy Conversion and Management, 52, 2296-2308, 2011.

19. Xiog J., Zhao H., Zheng C., "Thermoeconomic cost analysis of a 600 MWe oxy-combustion pulverized-coal-fired power plant", International Journal of Greenhouse Gas Control, 9, 469-483, 2012.

20. Xiog J., ve Ark., "Thermoeconomic operation optimization of a coal-fired power plant", Energy, 46, 486-496, 2012.

21. Singh O. A., Kaushik S. C., "Thermoeconomic evaluation and optimization of a Brayton-RankineKalina combined triple power cycle", Energy Conversion and Management, 71, 32-42, 2013.

22. http://www.turkseker.gov.tr, 2013.

Uche J., Serra L., Valero A., "Thermoeconomic optimization of a dual-purpose power and desalination plant", Desalination, 136, 147-158, 2001. 